\title{
BEAR1, a bHLH Transcription Factor, Controls Salt Response Genes to Regulate Rice Salt Response
}

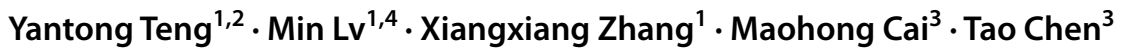

Received: 17 September 2021 / Revised: 4 December 2021 / Accepted: 16 January 2022 / Published online: 10 February 2022

(c) The Author(s) 2022

\begin{abstract}
Transcription factors play important roles in plant abiotic stresses. However, there are a large number of TF functions in rice salt response need to be characterized. Our study identified a new transcription factor, BEAR1, acts as a regulator of rice salt response. We used artificial microRNA to generate BEARl knockdown transgenic rice, and CRISPR to generate BEARl gene editing mutant lines. Both knockdown lines and mutant lines showed salt sensitive phenotypes, compared to NIP. Transient expression in rice protoplast was used to confirm the subcellular localization of BEAR1. The transcription activity of BEAR1 was detected by yeast system. BEARl was induced by salt stress and dominantly expressed in root at seedling stage and spikelet at mature stage. BEAR1 regulating rice salt response by controlling expression levels of many salt-related genes, including salt response marker genes and ion transporter genes. The study revealed that BEAR1 was a regulator of rice salt response.
\end{abstract}

Keywords BEAR1 $\cdot$ Rice $\cdot$ Seedling stage $\cdot$ Salt tolerance $\cdot$ Transcription factor

\section{Introduction}

Salt stress influences plant growth and development during the whole life cycle, which can result in growth retardation, membrane damage, ion balance turbulence, lipid peroxidation, ROS accumulation (Yang and Guo 2018). High salt level can be monitored by GIPC (glycosyl inositol phosphorylceramide) in the plant cell membrane. MOCA1, as a glucuronosyltransferase for GIPC, plays vital role in salt-induced membrane depolarization, and $\mathrm{Ca}^{2+}$ signal

Yantong Teng and Min Lv have contributed equally to this work.

Tao Chen

chentao@hznu.edu.cn

1 Biotechnology Research Institute, Chinese Academy of Agricultural Sciences, Beijing 100081, China

2 College of Life Sciences, Inner Mongolia University, Neimenggu 010040, China

3 Zhejiang Provincial Key Laboratory for Genetic Improvement and Quality Control of Medicinal Plants, College of Life and Environmental Science, Hangzhou Normal University, Hangzhou 311121, China

4 College of Life Sciences, Nankai University, Tianjin 300071, China transduction. The $\mathrm{Ca}^{2+}$ signal can be sensed by $\mathrm{Ca}^{2+}$-binding protein $\mathrm{SOS} 3$ and $\mathrm{SCaBP} 8$ in roots and shoots, respectively. $\mathrm{SOS} 3 / \mathrm{SCaBP} 8$ then recruits and activates SOS2, a protein kinase. The activated form of SOS2 can phosphorylate plasma membrane $\mathrm{Na}^{+} / \mathrm{H}^{+}$anti-porter SOS1, vacuolar $\mathrm{Na}^{+} /$ $\mathrm{H}^{+}$anti-porter NHX and vacuolar $\mathrm{H}^{+}$-ATPase. The SOS pathway is vital for cytoplasmic $\mathrm{Na}^{+} / \mathrm{K}^{+}$homeostasis and plant adaptation under salt stress (Zhu 2016).

Salt stress also can rapidly induce ROS generation, which is harmful for plant cell. Hence, the scavenging of ROS plays important role in the plant adaptation formation in high salt circumstance (Miller et al. 2010). Many proteins were considered as a sensor of redox state in plant cell, which include heat shock transcription factor Hsf4a, S-sulfocysteine synthase CS26, thylakoid-associated thioredoxin-type protein ACHT1, protein kinase p46-MAPK, glutathione peroxidases GPX3 and others (Bermudez et al. 2010; Dangoor et al. 2012; Livanos et al. 2014; Miao et al. 2006; Miller and Mittler 2006). ROS scavengers participate in active-oxygeninduced cell damage repair. NCA1, a chaperone protein, can interact with CAT2 and increase the enzyme activity of $\mathrm{H}_{2} \mathrm{O}_{2}$ degradation (Li et al. 2015).

Transcription factors, as well as other gene expressionregulating components, are vital for plant adaptation to abiotic stresses (Yamaguchi-Shinozaki and Shinozaki 2006). 
Many subfamilies of transcription factors are well known as abiotic stress regulators, including AP2/ERF, NAC, WRKY, MYB and bHLH (Huang et al. 2012). The conserved bHLH domain in bHLH subfamily consists of 50-60-amino acid residue, which can be divided into basic amino acid residue at $\mathrm{N}$ terminus and helix-loop-helix domain at $\mathrm{C}$ terminus. The $\mathrm{E}$ box (CANNTG), especially $\mathrm{G}$ box (CACGTG), is the core binding motif of bHLH (Atchley et al. 1999; Carretero-Paulet et al. 2010; Massari and Murre 2000). Several bHLH transcription factors are discovered in plant salt stress response, such as AtbHLH39, AtbHLH112, NtbHLH123, VvbHLH1, CsbHLH1, PebHLH35, etc. (Cui et al. 2018; Dong et al. 2014; Wang et al. 2016; Xu et al. 2014; Zhai et al. 2016; Zhao et al. 2018).

Salt stress is one of the most common environmental stimuli in rice cultivation. There is a large difference in the whole process of rice growth and development. The most two sensitive stages are seedling stage and flowering stage (Todaka et al. 2012). Dozens of salt tolerant genes were cloned and characterized, function as signal transduction, transcription regulation, ion transportation, metabolic pathway and others (Ganie et al. 2019; Kumar et al. 2013; Todaka et al. 2012; van Zelm et al. 2020) Negative transcription regulators, such as OsIDS1, OsWRKY1, OsWRKY45-2, participate in salt stress response by repressing target gene expression (Cheng et al. 2018, 2021; Qiu et al. 2007, 2008). Positive transcription regulators, such as OsCOIN, OsDREB2A, OsMYB2, OsbZIP71, OsbZIP23, increase the ability of rice salt adaptation by promoting the accumulation of Osmotic protective substances and antioxidant, increasing $\mathrm{Na}^{+} / \mathrm{K}^{+}$transporter activity, enlarging biomass (Liu et al. 2014a, b; Liu et al. 2007; Mallikarjuna et al. 2011; Xiang et al. 2008; Yang et al. 2012).

Here, we report BEAR1, a bHLH transcription factor, plays important role in rice salt stress response. The knockdown lines of BEARI showed remarkably salt sensitive phenotypes and confirmed by CRISPR lines. BEAR1 was localized in nuclear and had a transcription activation function. The expression pattern was detected at both seedling stage and mature stage. BEARl expression level was induced by $\mathrm{NaCl}$ treatment. The expression levels of stress response marker genes were differentially regulated between NIP and BEAR1 mutant material.

\section{Results}

\section{Identification of BEAR1 as a Regulator of Rice Salt Tolerance}

We screened the whole transcription factors for salt stress response (Cheng et al. 2018). In addition to an AP2/ERF family protein IDS1, we also found BEAR1, a bHLH TF, was regulated by salt stress signal. To confirm the potential role of BEAR 1 in rice salt tolerance, we created artificial microRNA (amiRNA) construct using pNW55 as a backbone vector. We used WMD3 (Web MicroRNA Designer) to calculate the best artificial microRNA target site, followed by designing 4 primers to amplify mimic miRNA528 with designing artificial microRNA sequence (TCCATCAAT GGCGCCTAGAGCG). As shown in Fig. 1A, the amiRNA target site was located in the 3rd exon of BEARl genomic DNA. The amiRNA sequence was perfectly matched the target site. The strategy of artificial pri-miRNA generation was presented in Fig. 1B. OsaMIR528 gene was used as a template. The sequence was subcloned into plant binary vector pCAMBIA1302 and we named the construct pBEAR1-ami. The pBEAR1-ami transgenic lines were generated using the rice ssp. japonica cv Nipponbare (NIP) as background. Based on the artificial microRNA knockdown function to target gene, we checked the expression level of BEARI in all transgenic lines. BEARl level in 3 transgenic lines, BEAR1ami2, BEAR1-ami8, BEAR1-ami9 were decreased to 9-15\% compared to NIP (Fig. 1C).

The 3 transgenic lines were selected for further salt treatment. 3-week-old seedlings of NIP and knockdown lines in pots were washed with $150 \mathrm{mM} \mathrm{NaCl}$ and recovered by water. As shown in Fig. 2A, all of the 3 amiRNA lines were much more sensitive to salt, seedling growth were greatly obstructed and plant heights were significantly lower than NIP (Fig. 2B). After recovery with water, NIP rejuvenated rapidly while most seedlings of 3 amiRNA lines were dead, the survival rates showed in Fig. 2C. Osmotic reagents concentration and plasma membrane integrality were important features of salt tolerance. We measured the content of proline and malondialdehyde (MDA) in NIP and amiRNA lines. As shown in Fig. 2D and E, proline decreased and MDA increased in knockdown lines when compared with NIP. These results illuminated that BEAR1 was a positive regulator of rice salt tolerance.

\section{Characterization of BEAR1 as a Transcription Factor}

To confirm BEAR1 as a transcription factor, we made a BEAR1-YFP fusion construct by the gateway LR reaction. Rice protoplasts were isolated from etiolated seedlings and BEAR1-YFP fusion proteins were expressed by PEG-mediated transient expression. NLS-mCherry was used as nucleus location marker. As shown in Fig. 3A, BEAR1 was co-localized with nucleus marker protein in rice protoplast. To verify the transcription activity of BEAR1, we constructed BEAR1 into pGBKT7, which was named pBEAR1, and transformed into yeast cells AH109. As shown in Fig. 3B, BEAR1 demonstrated transcription activation factor as positive control $(\mathrm{ck}+)$. 
(a)

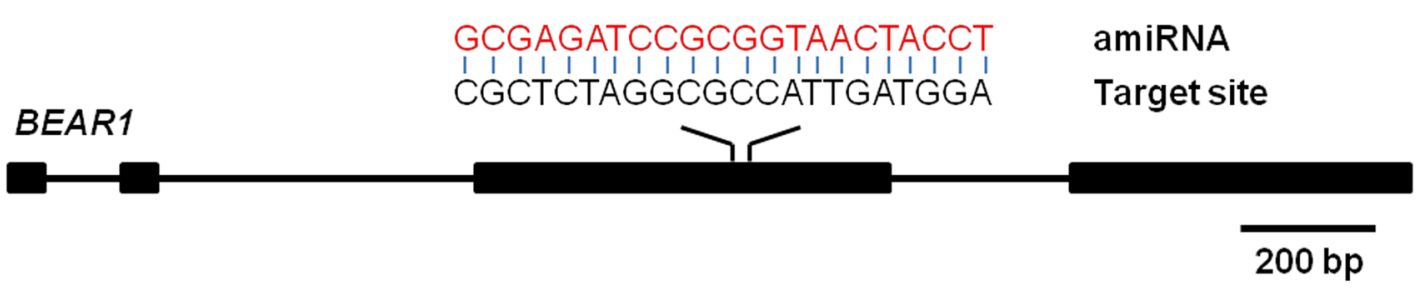

(b)

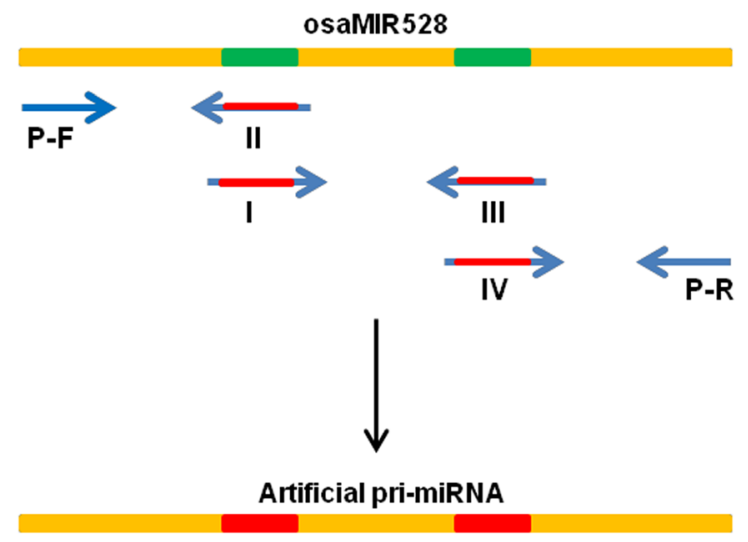

(c)

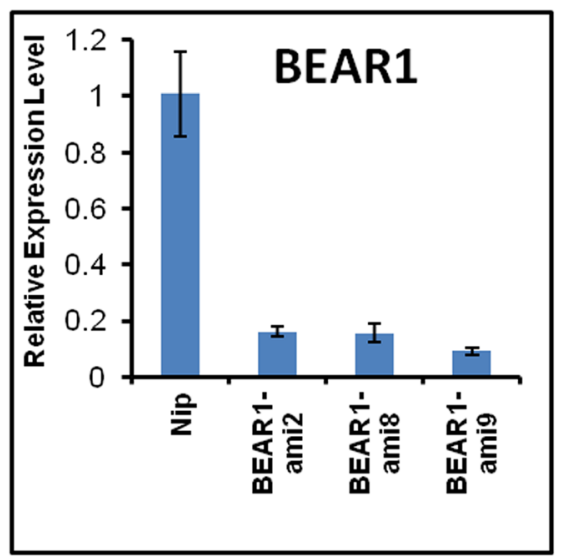

Fig. 1 Generation of BEAR1 amiRNA lines. A Selection of amiRNA target site. The target site on diagram of BEAR1 genomic DNA was presented. B The strategy of artificial microRNA generation. Four BEAR1 target site-specific primers (I, II, III and IV) were designed as protocol and 3 fragments were amplified using P-F and II, I and IV, III and P-R. Then, the fragments were used as templates to amplify

\section{Spatiotemporal and Stress Expression Pattern of BEAR1}

Since BEAR1 was verified as a transcription factor, we wanted to discover the expression patterns of BEARl gene in rice. Total RNA was isolated from different tissues of developmental stages, such as root and shoot at the juvenile stage, root, stem, leaf spikelet and seed at reproductive stage. As shown in Fig. 3C, BEARl was dominantly expressed in root at seedling stage, which was 3 times compared with seedling shoot. At reproductive stage, BEARl was mostly expressed in spikelets. Due to the roles in rice salt response, we checked the BEAR1 expression levels in salt stress treatment. We found that, with the salt treatment lasting, BEARI was constantly induced with expression peak at $6 \mathrm{~h} \mathrm{NaCl}$ treatment (Fig. 3D).

\section{Generation of BEAR1 CRISPR Lines}

To confirm the salt sensitive phenotypes of BEAR1 amiRNA knockdown lines, we created BEAR 1 mutant lines by CRISPR-Cas9 method. Using CRISPR-GE (http://skl.scau. edu.cn/) online, we screened the best target site of BEARl. the full length of artificial microRNA using P-F and P-R as primers. C The knockdown efficiency of 3 amiRNA lines. Seedling materials of NIP and 3 amiRNA lines were harvested. After RNA extraction and reverse transcription, real-time qPCR assays were performed and $A C T 2$ was used as the internal control. Error bars represent $\mathrm{SD}(n=3)$

As shown in Fig. 4A, BEARl genomic DNA diagram was presented and the target site (GGCTCTCGTCGACCGTAT CA) at the 3rd exon, which corresponding to $132-151 \mathrm{bp}$ in BEAR1 coding sequence. At the protein level, the target site located at 44-50 a.a. of BEAR1 protein, which was outside of the bHLH domain (Fig. 4B). Following constructs generation, Agrobacterium-mediated transformation was used to create BEAR1 CRISPR lines. We sequenced the lines and two independent lines were selected for further experiments. As shown in Fig. 4C-E, one line with 1nt deletion at the target site, was named BEAR1-M1; another line, with 1nt insertion, was named BEAR1-M2. The single peak represented that two lines were homozygous lines. To test if the RNA level was changed in mutant line, we extracted total RNA and examined BEARI expression by real-time qRT-PCR. As shown in Fig. 4F, BEARI was decreased in two mutant lines, which may be caused by NMD pathway mRNA decay initiated by pre-mature stop codon in BEARl mRNA. 
Fig. 2 The salt sensitive phenotype of BEAR1 amiRNA lines. A Salt sensitive phenotype of BEAR1 amiRNA lines. The seedlings of NIP and amiRNAmediated BEAR1 knockdown lines ami2, ami8 and ami9 were treated with or without $150 \mathrm{mM}$ $\mathrm{NaCl}$ for 10 days followed by recovery with water for another 10 days. B The statistical results of seedling heights under salt treatment. Error bars represent $\mathrm{SD}(n \geq 30)$. C The statistical results of survival rates after recovery from water. Error bars represent $\mathrm{SD}(n \geq 30)$. D and $\mathbf{E}$ The proline and MDA (malondialdehyde) contents of NIP and amiRNA lines with or without salt treatment. Error bars represent SD among three independent replicates. $* *$, $P<0.01$ (Student's test) (a)

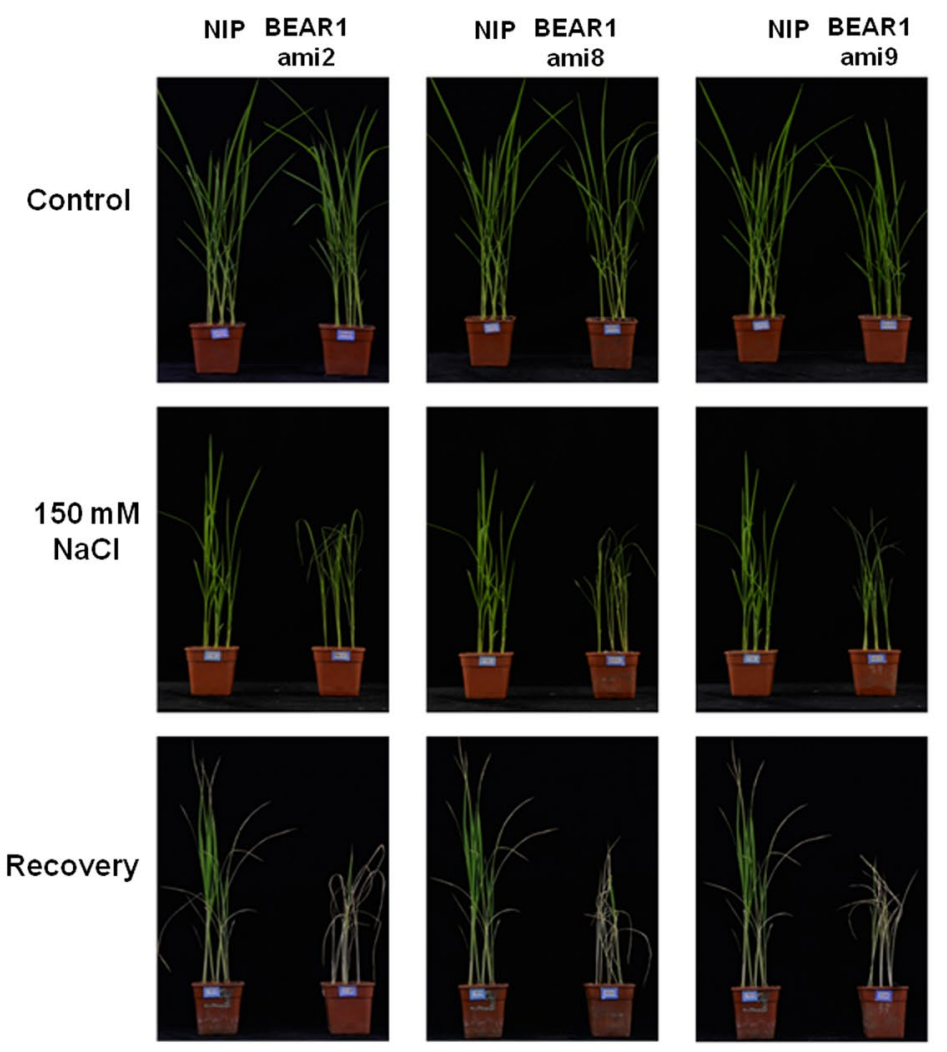

(b)

(c)
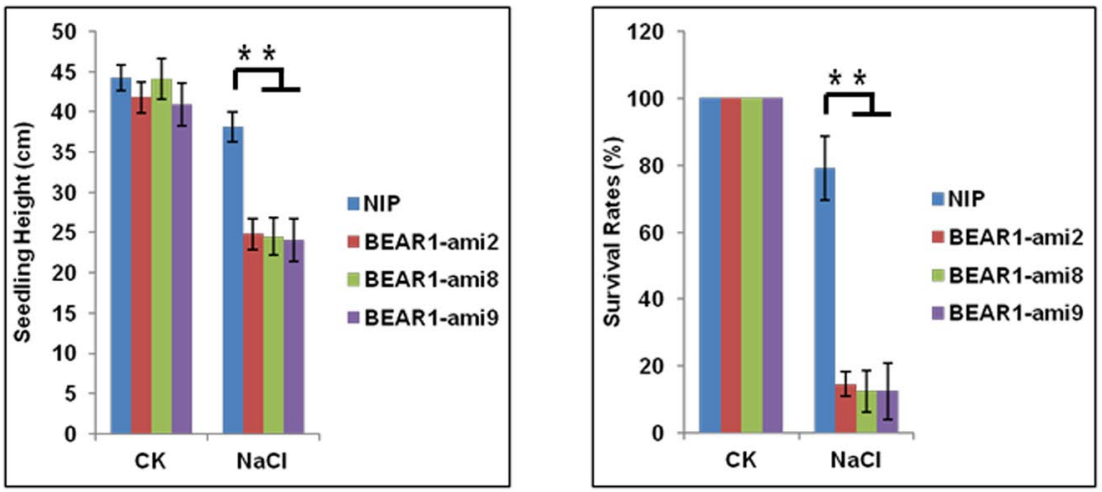

(d)

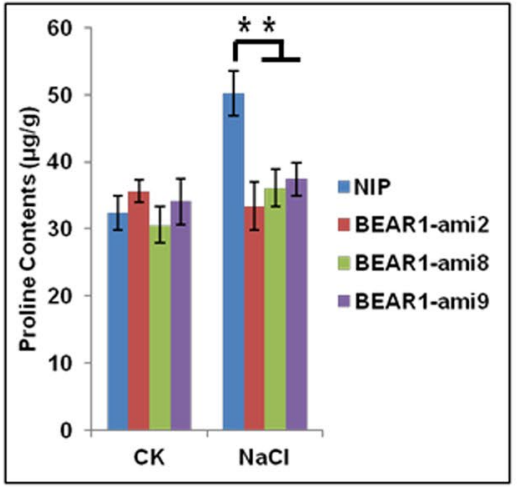

(e)

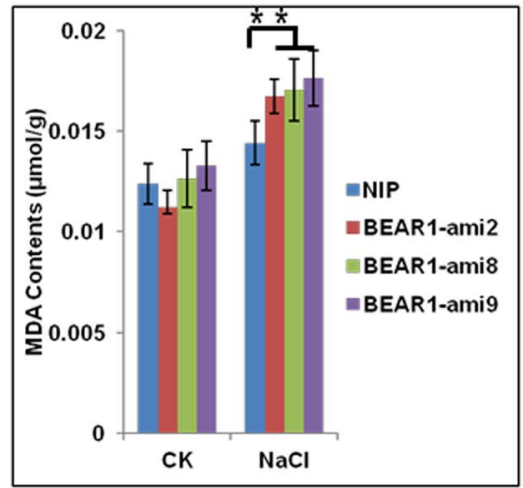


(a)

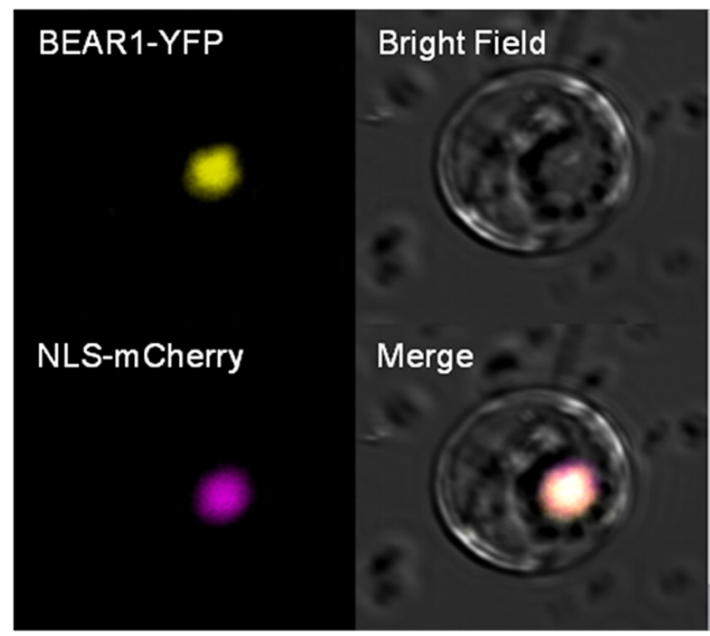

(c)

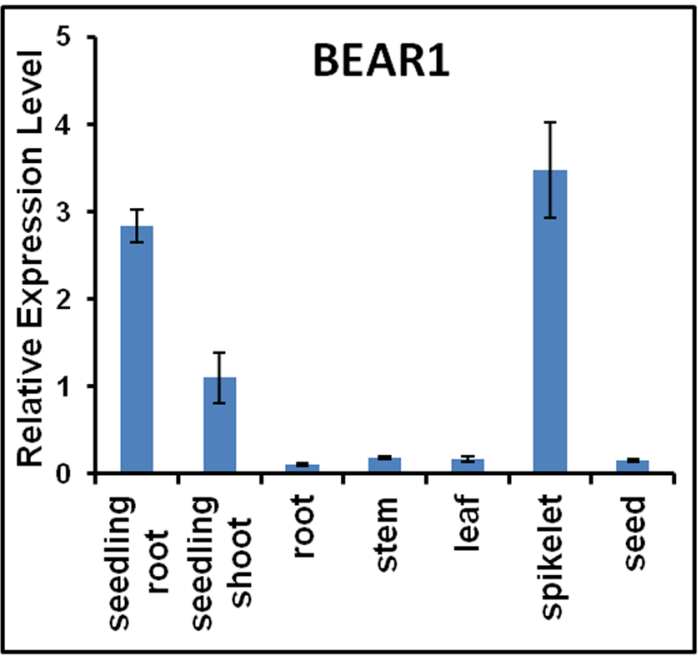

(b)
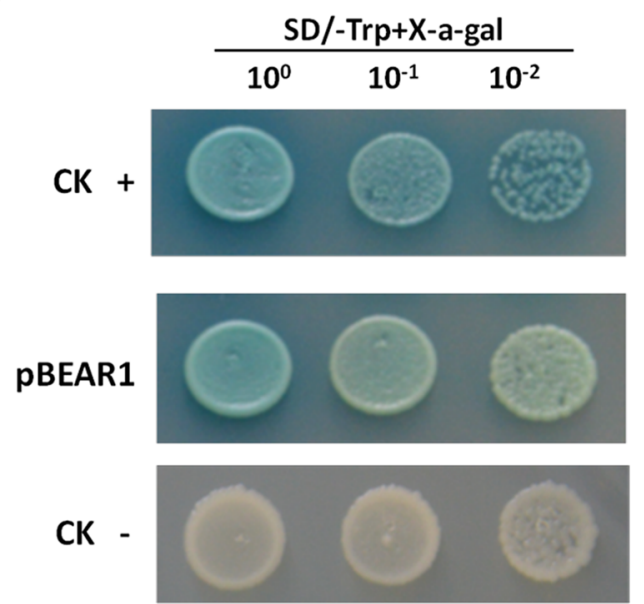

(d)

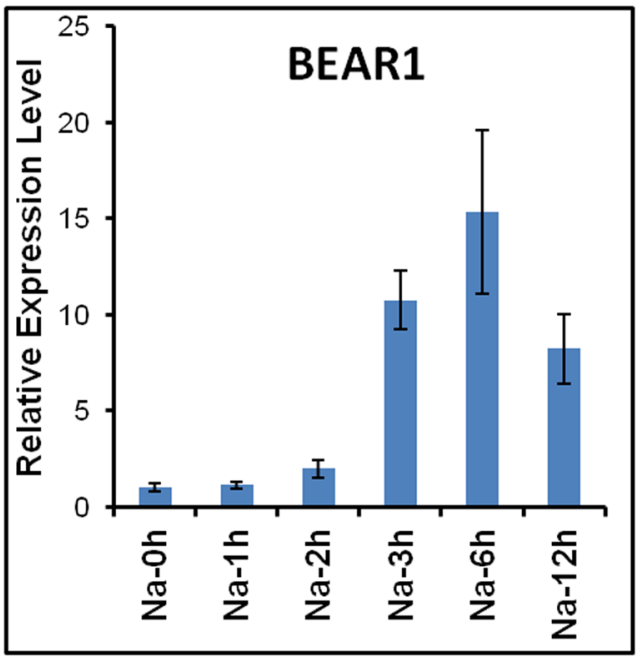

at different stages. Tissues at different stages were collected. After RNA extraction and reverse transcription, real-time qPCR assays were performed and $A C T 2$ was used as the internal control. D BEARI expression pattern under salt treatment. 10-day-old seedlings were treated with $150 \mathrm{mM} \mathrm{NaCl}$ with the time course. After RNA extraction and reverse transcription, real-time qPCR assays were performed and ACT2 was used as the internal control. Error bars represent SD $(n=3)$

$150 \mathrm{mM} \mathrm{NaCl}$ stress. We could see from Fig. 5B, with NIP was almost unaffected, the growth of $\mathrm{M} 1$ and $\mathrm{M} 2$ were suppressed to $63 \%$ of height at $75 \mathrm{mM} \mathrm{NaCl}$ condition, compared to normal condition. After 10 days recovery with water, the survival rates showed most significant at $150 \mathrm{mM}$ $\mathrm{NaCl}$ condition (Fig. 5C). We measured the content of proline and MDA in NIP and mutant lines. The proline contents decreased in mutant lines M1 and M2, as well as MDA contents increased in mutant lines when compared with NIP, under salt condition (Fig. 5D and E). 
(a)

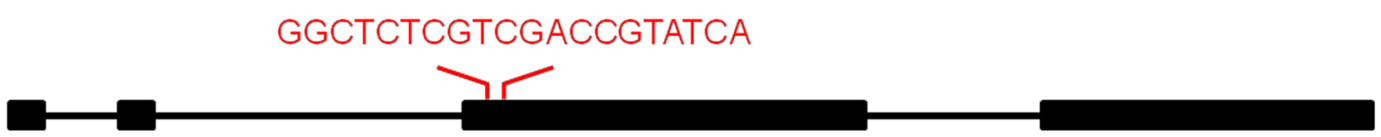

$200 \mathrm{bp}$

(b)

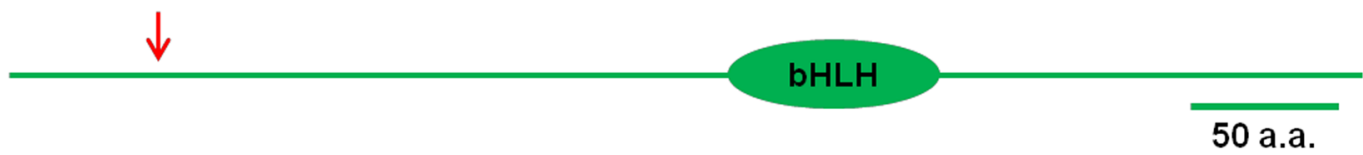

(c)

(d)

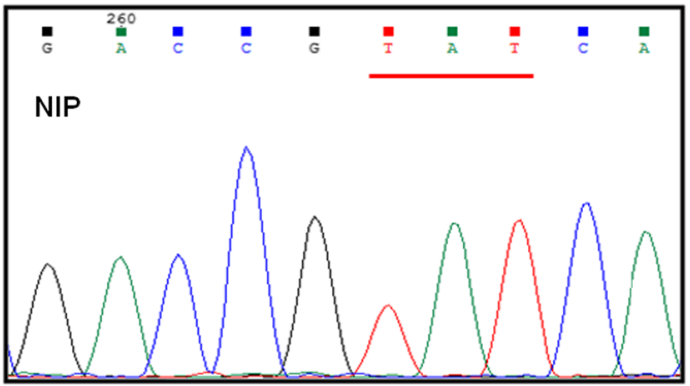

(e)

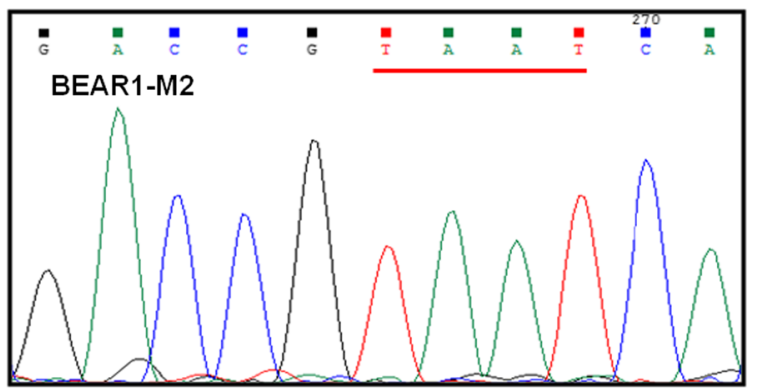

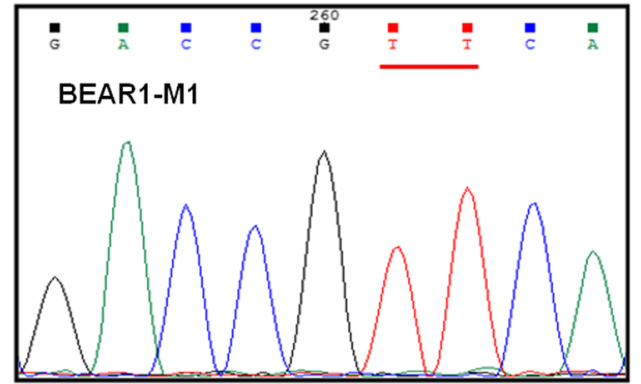

(f)

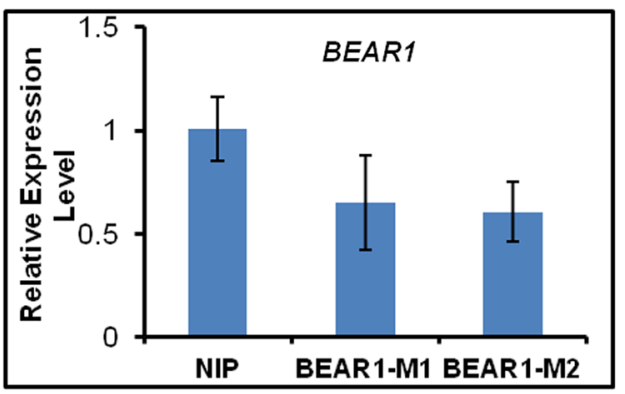

Fig. 4 Generation of BEAR1 CRISPR lines. A CRISPR target site on BEAR1 genomic DNA. The gRNA was designed on the third exon of BEAR1 genomic DNA. B The corresponding mutation site of BEAR1 protein. $\mathbf{C}-\mathbf{E}$ Sequencing confirmation of BEAR1 CRISPR lines. C The wild-type NIP sequence of target site; D, the edited sequence with deletion in BEAR1-M1 CRISPR line; $\mathbf{E}$ the edited sequence with insertion in BEAR1-M2 CRISPR line. F BEAR1 expression levels in NIP and CRISPR lines. 10-day-old seedlings were harvested. After RNA extraction and reverse transcription, realtime qPCR assays were performed and $A C T 2$ was used as the internal control. Error bars represent $\mathrm{SD}(n=3)$

\section{Differentially Regulated Response of Root and Leaf Under Salt Stress}

Due to the different response mechanism of shoot and root to salt stress, we harvested seedling root and seedling leaf samples which were bearing salt stress. Total RNA was extracted and the cDNA libraries were generated by standard protocols. After sequencing, the RAW data were trimmed and clean data. Following quality control, the clean data were mapped to rice reference genome by HISAT2. Principal component analysis (PCA) showed that replicates in the same group were clustered together (Fig. 6).

We first checked genes expression pattern between NIP and M1 under salt stress. The volcano map showed that the differentially expressed genes in seedling root part were 675 , in which 295 genes were up-regulated and 380 genes were down-regulated (Fig. 7A). Meanwhile, the differentially expressed genes in seedling leaf part were 1886, and downregulated genes were 1482 which accounted for the majority of total differentially expressed genes (Fig. 7B). Cluster analysis of differential genes was performed to gather genes with similar expression patterns. These genes had similar functions or participate in same metabolic pathways and signal pathways. In the heat map, red indicates high expression and blue indicates low expression. Cluster analysis of differential genes was presented as heat map and showed in Fig. 7C and D. All differentially expressed genes, in seedling root part and seedling leaf part, are listed in Table S2 
Fig. 5 Confirmation of BEAR1 salt response by CRISPR lines. A The salt phenotypes of BEAR1 CRISPR lines. The seedlings of NIP and BEAR1 CRISPR mutant lines BEAR1M1 and BEAR1-M2 were treated with different concentration of $\mathrm{NaCl}$ for 10 days. B The statistical results of seedling heights under salt treatment. Error bars represent $\mathrm{SD}(n \geq 30)$. C The statistical results of survival rates after recovery from water. Error bars represent $\mathrm{SD}(n \geq 30)$. D and $\mathbf{E}$ the proline and MDA contents of NIP and CRISPR lines under salt treatment. Error bars represent SD among three independent replicates. $* *, P<0.01$ (Student's test) (a)
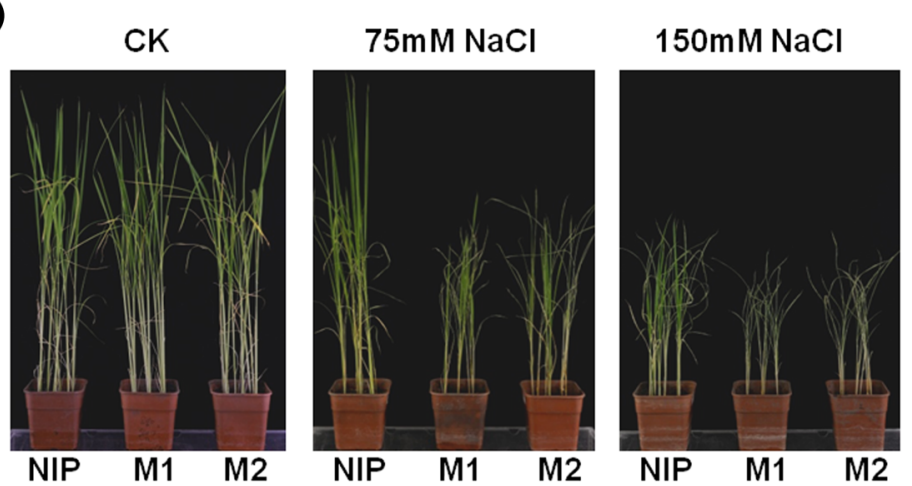

$250 \mathrm{mM} \mathrm{NaCl}$

(b)

(c)
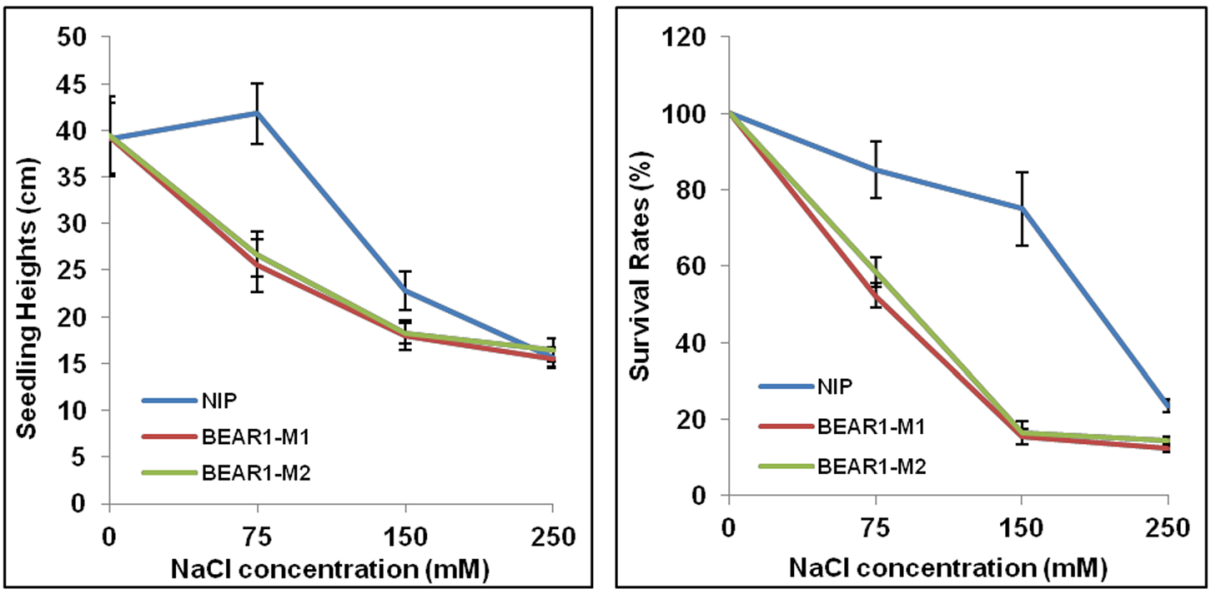

(d)

(e)

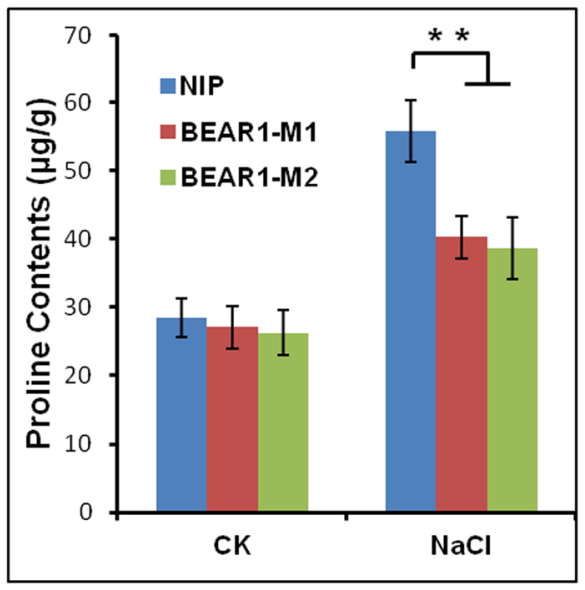

and Table S3. From these data, we could conclude that M1 mutant line was sensitive to salt due to the genes downregulation under salt stress especially the shoot part of rice.

We also analyzed seedling root samples and seedling leaf samples separately. As shown in Fig. 8A, most differential expressed genes were overlapped between NIP-root-NaCl/ NIP-root-H2O and M1-root-NaCl/M1-root-H2O, which mean that under salt stress, most gene expression pattern were same between NIP and M1 CRISPR line. Meanwhile, in seedling leaf tissue, we could not find a dominant section of differential genes (Fig. 8B), which was consistent with Fig. 7.

Since we showed that the difference of gene expression pattern between root tissue and leaf tissue of NIP and M1 mutant line, we performed KEGG analysis. As shown in Fig. 8C and $\mathrm{D}$, the number of KEGG enrichment of differential genes in leaf tissue was more than root tissue, which 58 genes were classed into the biosynthesis of secondary metabolites in leaf, 


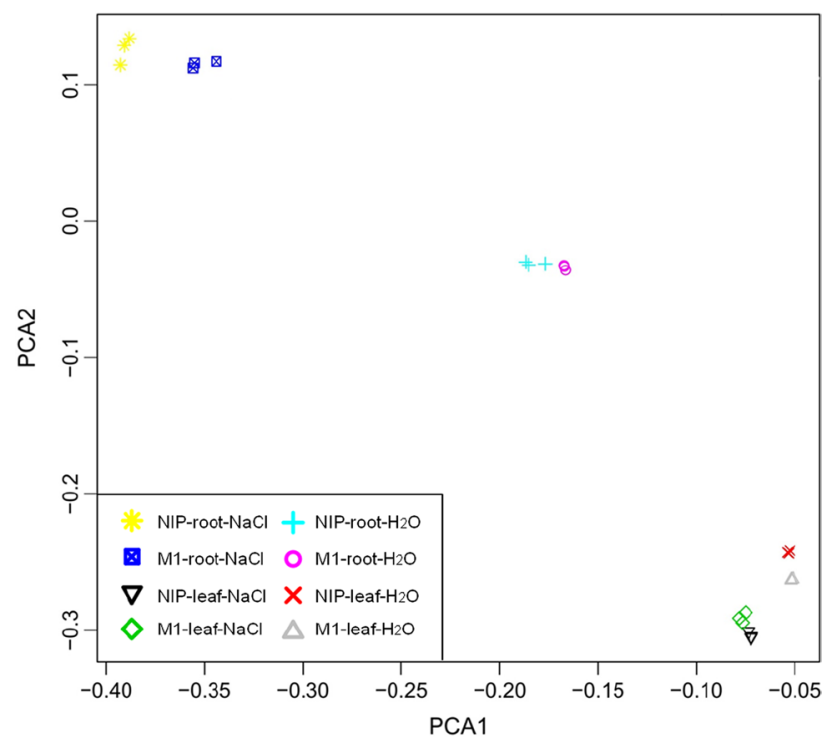

Fig. 6 Principal component analysis of samples. All samples were harvested with or without $250 \mathrm{mM} \mathrm{NaCl}$ treatment for $3 \mathrm{~h}$. Total RNA was extracted and cDNA libraries were generated, followed by next-generation sequencing. Clean data were processed and principal component analysis was performed to show repeatability of replicates

comparing with 24 genes classed into metabolic pathways in root. Indicated by red asterisk, there were 4 pathways with more than 10 genes were clustered in leaf tissue while only 2 pathways were presented in root tissue.

Due to the transcription activation function of BEAR1 and most differential genes were down-regulated in seedling shoot part, we assumed that these down-regulated genes may be the target or affected genes of BEAR1. We pay special attention to the Gene ontology (GO) analysis of these genes. Figure 9A showed the GO analysis of down-regulated genes in $\mathrm{M} 1-$ root-NaCl/NIP-root-NaCl comparison. We could see that the most clustered section in BP (biological processes), MF (molecular function) and CC (components of cell) were 44 genes, 36 genes and 46 genes, corresponding to cellular component organization, oxidoreductase activity and cell periphery, respectively. At leaf tissue, the down-regulated genes were classified by GO analysis and red asterisk indicated the section which had more than 100 genes clustered (Fig. 9B). The most clustered section in BP, MF and CC were 320 genes, 720 genes and 532 genes, respectively. These data demonstrated that the salt sensitive phenotype of CRISPR lines maybe caused by the response differential genes in leaf tissue.

\section{Salt Response Marker Genes were Differential Expressed in NIP and CRISPR Lines}

To find the molecular mechanism of BEAR1 in rice salt response, we performed real-time qRT-PCR for checking salt response genes and regulators. As shown in Fig. 10A, many salt response genes, such as DREB1F, LEA3, bHLH120 etc., were slightly increased in mutant lines M1 and M2, while the genes were increased dramatically in NIP under salt stress. The expression levels of ion transporter genes, HAK6 and NHX4, were also lower in mutant lines.

We proposed a model for the function of BEAR1 in rice salt response. After receiving the salt stress signal, BEAR1 protein controlled the gene expression level of salt response signaling cascade on one hand, and regulated the $\mathrm{Na}^{+} / \mathrm{K}^{+}$ balance and membrane stabilization genes on the other hand (Fig. 10B).

\section{Discussion}

From the rice transcription factor database, we identified BEAR 1 as a salt response gene under salt stress. We generated BEAR1 amiRNA construct and created BEAR1 amiRNA lines, of which ami2, ami8 and ami9 lines were selected for salt treatment. We discovered the salt sensitive phenotype of under salt treatment and recovery by water. The results were confirmed by CRISPR lines of BEAR 1 .

We also verified the nuclear localization by transient expression in rice protoplast. The transcription activation assay was performed in yeast system, and VP16 was used as positive control. Clearly, BEAR1 had the transcription activation function, but weaker than VP16. Many salt response marker genes, such as SNAC1, LEA3, were differential regulated between NIP and amiRNA lines when suffering salt stress.

The bHLH family was the second largest family in plant world, and there were 176 members in rice which were consist of 22 subfamilies (Li et al. 2006). Many of bHLH proteins played roles in salt tolerance. In Arabidopsis, AtNIG1, AtbHLH122 and AtMYC2 over-expression confers increased salt tolerance. These proteins were regulator $\mathrm{Na}^{+} / \mathrm{H}^{+}$antiporter, such as AtNHXI and AtNHX6 (Kim and Kim 2006; Krishnamurthy et al. 2019; Liu et al. 2014a, b; Verma et al. 2020). In rice, OrbHLH001, which was a gene from Dongxiang wild rice (Oryza rufipogon Griff.), enhanced rice salt tolerance by regulating the expression level of OsAKT1 (Li et al. 2010). ZmbHLH55 in maize and SlbHLH22 in tomato improved plant salt tolerance by over-expression (Waseem et al. 2019; Yu et al. 2021). From Fig. 4, we could find that BEAR1 may share the same molecular mechanism of salt response as OrbHLH001, AtbHLH122 and AtMYC2.

In conclusion, we found a new gene, which participated in rice salt response from transcription factor screening. BEAR1 was verified as a salt regulator in rice and the SNP of BEAR1 in cultivated varieties can be used as a molecular marker for rice salt tolerance breeding. 
Fig. 7 Volcano and heat map of differential genes under salt stress. A and $\mathbf{B}$ the volcano map showed that the differentially expressed genes in seedling root part (A) and leaf part (B). Green dot represents down-regulated genes, red dot represents upregulated genes. $\mathbf{C}$ and $\mathbf{D}$ the heat map showed the expression patterns of transcripts in seedling root part (C) and leaf part (D). Red indicates high expression and blue indicates low expression. The expression levels of all transcripts were rescaled by $\log 10$ (a)

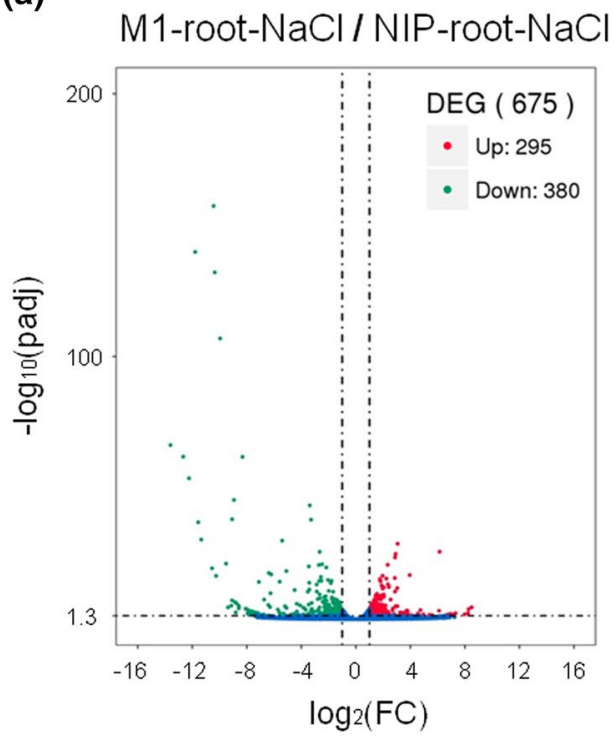

(c)

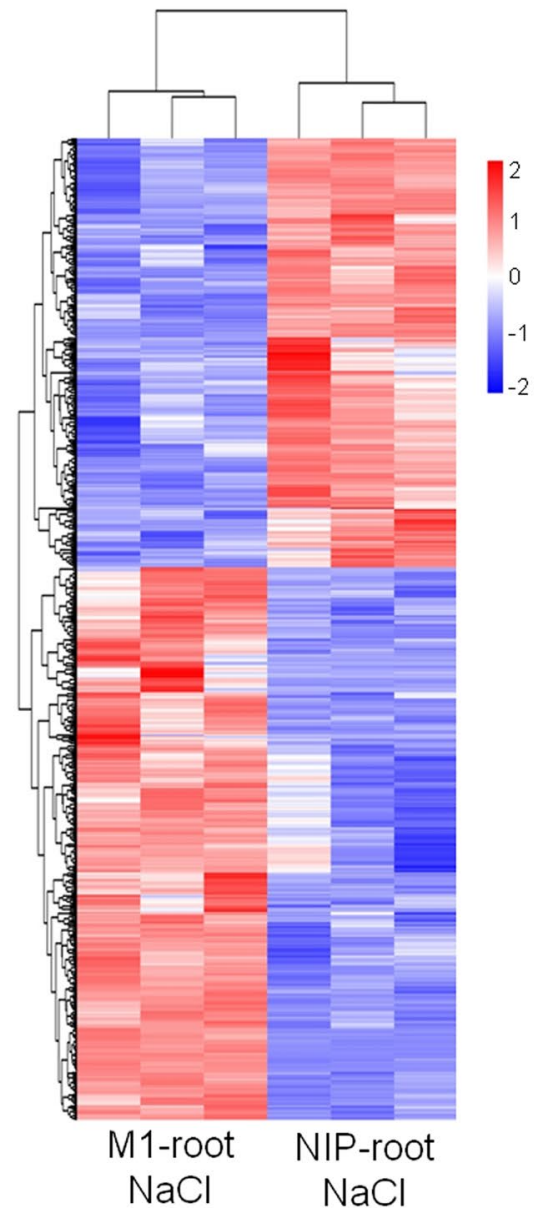

(b)

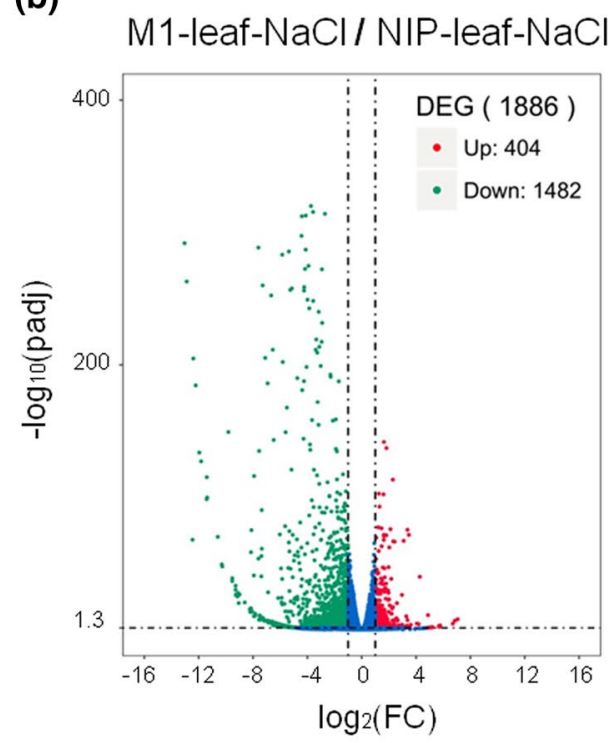

(d)

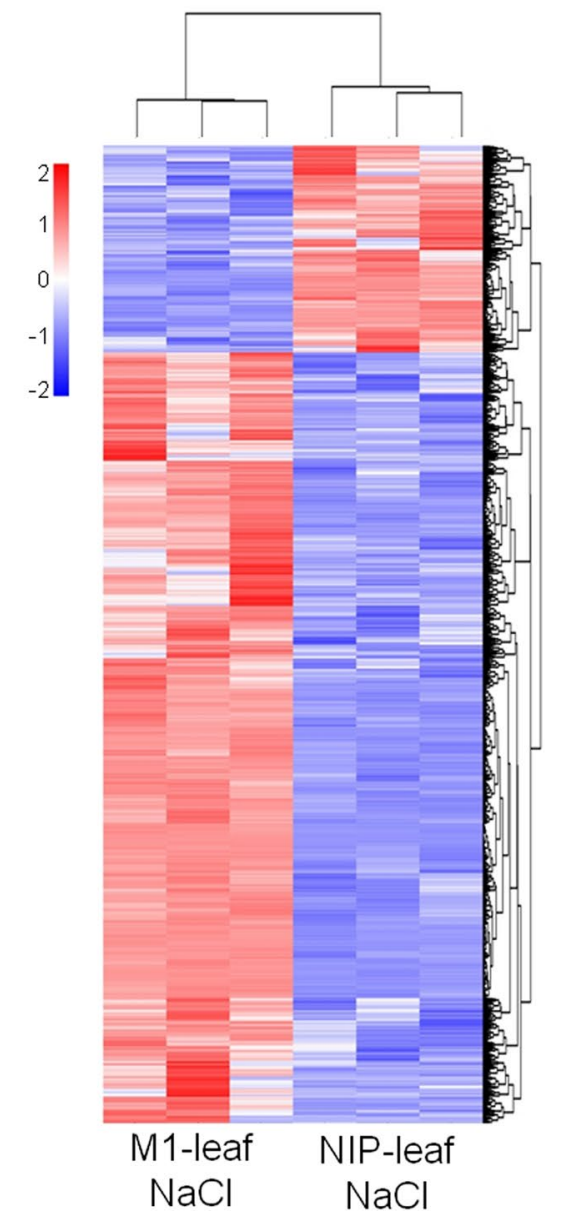


(a)

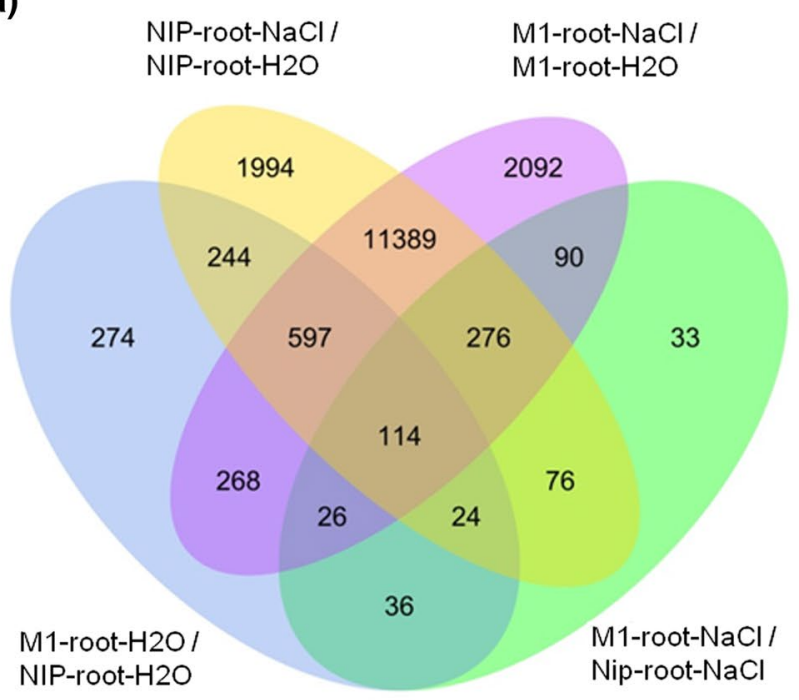

(c)

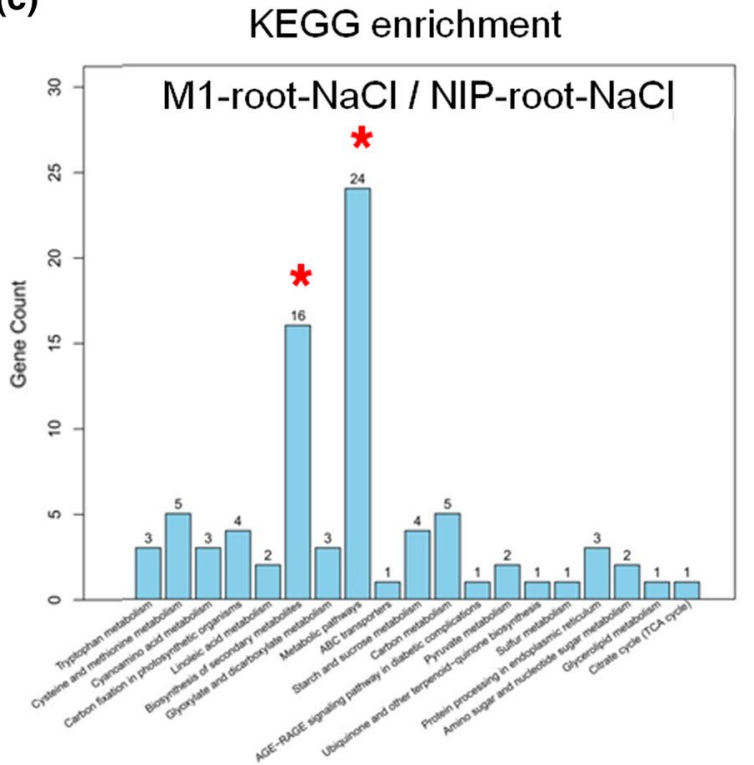

Fig. 8 Venn diagram and KEGG enrichment of root and leaf under salt stress. A and B Venn diagram of the overlap of differential expression genes of NIP and BEAR1 CRISPR lines seedling root and

\section{Materials and Methods}

\section{Plant Material and Salt Treatment}

The rice seeds were immersed into water for imbibitions and keep at $37{ }^{\circ} \mathrm{C}$ for 2 days for germination. After the appearance of coleoptiles, the germinated seeds were transferred to soil in the pots under $13 \mathrm{~h}-28^{\circ} \mathrm{C}-$ light $/ 11 \mathrm{~h}-24^{\circ} \mathrm{C}$-dark program in a greenhouse. (b)

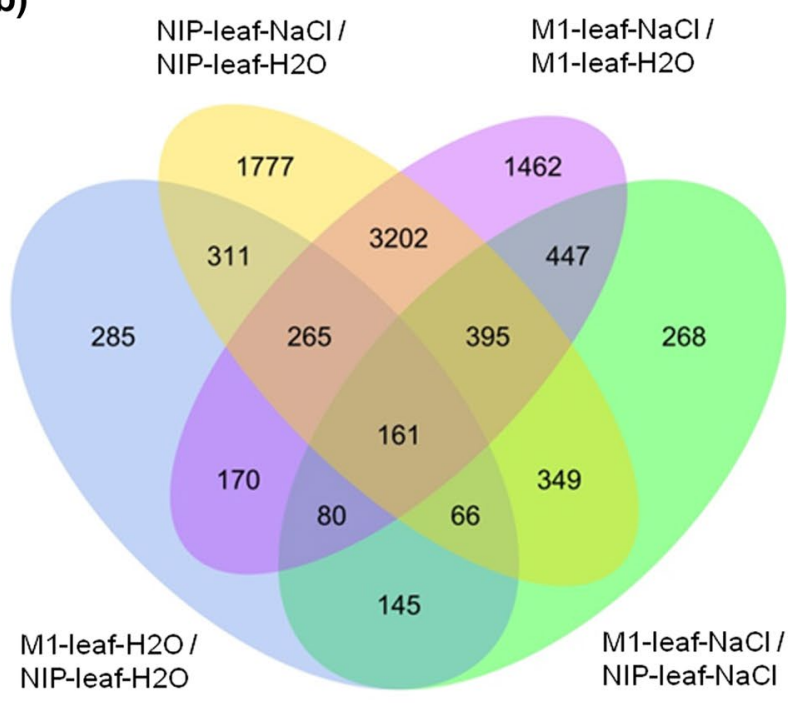

(d)

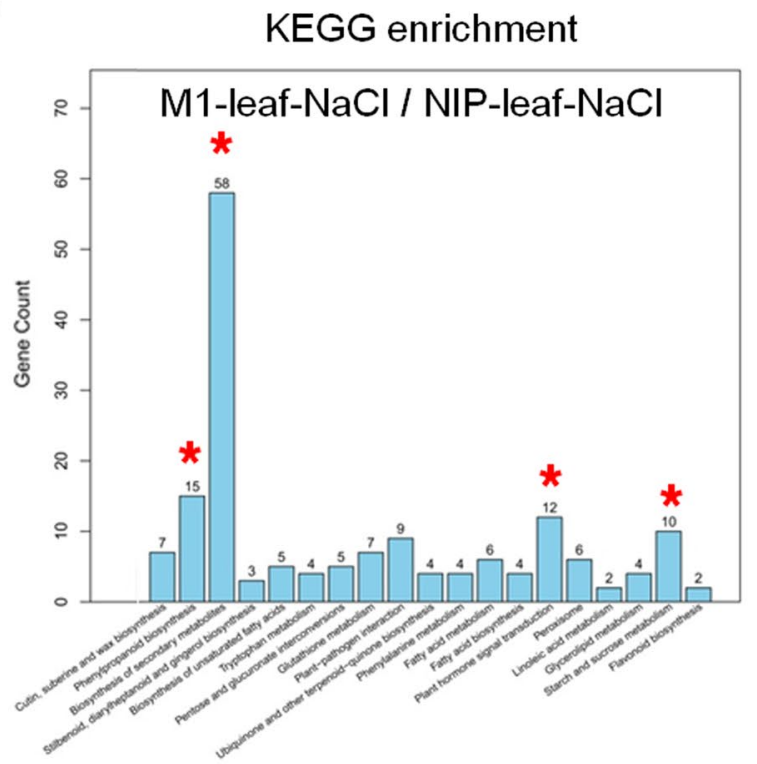

leaf with $\mathrm{NaCl}$ treatments. C and D KEGG enrichment of seedling root and leaf under salt stress. Red asterisk represented more than 10 genes were clustered

To compare the difference of salt tolerance phenotype between NIP (Oryza.Sativa L.spp.japonica,var Nipponbare) and mutants materials, the 3 -week-old rice seedlings were treated with different concentration of $\mathrm{NaCl}$ for 10 days and recovered to normal condition by replacing the salt solution with water for another 10 days. The seedling height and survival rate were recorded and calculated. The malondialdehyde (MDA) and proline contents were measured before recovery, according to the standard determination methods (Abraham et al. 2010; Li et al. 2011). 

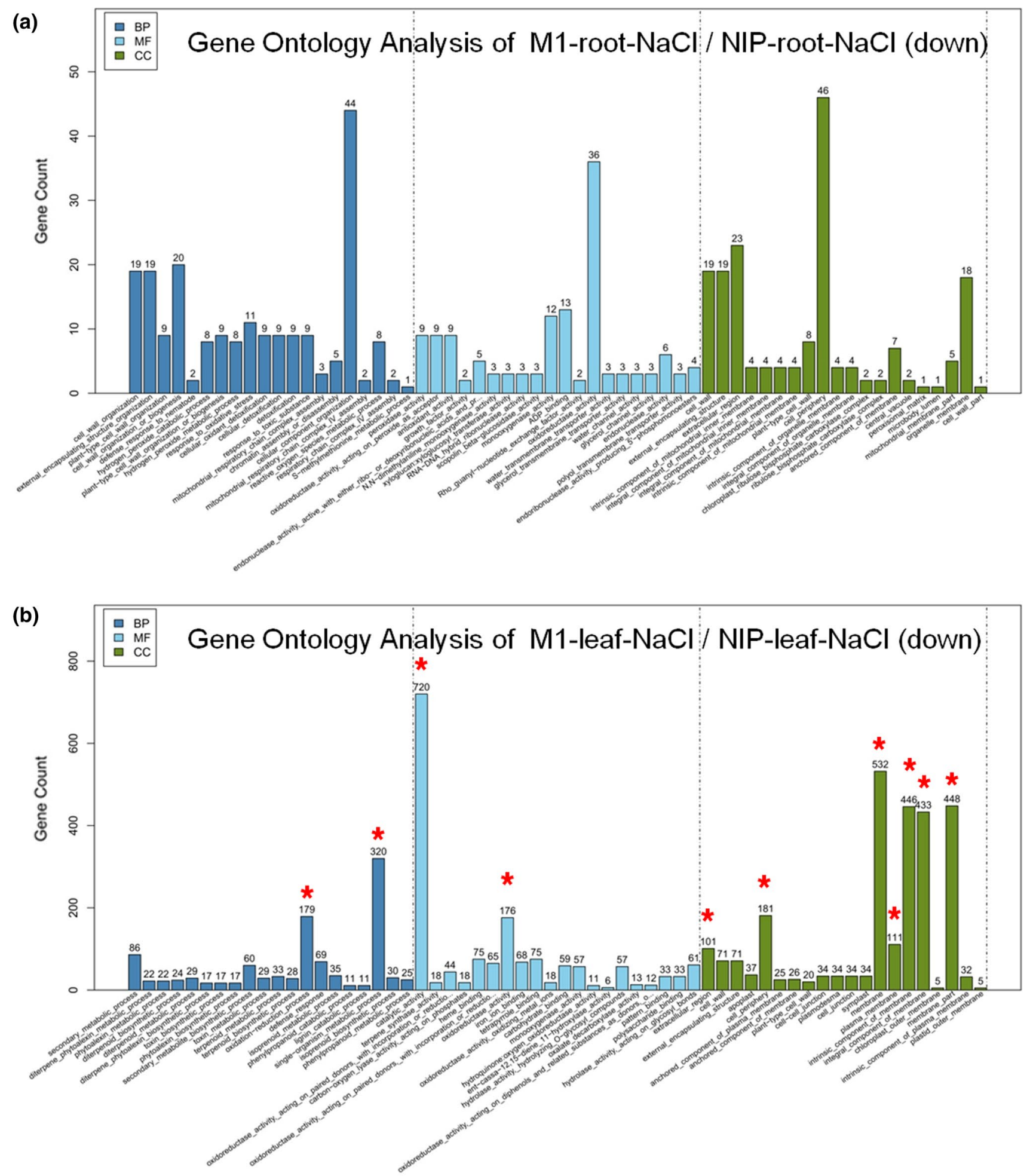

Fig. 9 GO enrichment of NIP and BEAR1 CRISPR line under salt stress. Genes differentially expressed in seedling root (A) and seedling leaf (B) with salt stress were categorized and annotated based on biological processes (blue part), molecular functions (cyan part), and cellular components (green part). Red asterisk represented GO plant term which $>100$ genes were clustered 
Fig. 10 Salt response marker genes were down-regulated in BEAR1 mutant lines. A Saltrelated genes expression in NIP and CRISPR lines under salt treatment. 10-day-old seedlings were treated with $150 \mathrm{mM} \mathrm{NaCl}$ for $3 \mathrm{~h}$. After RNA extraction and reverse transcription, real-time qPCR assays were performed and $A C T 2$ was used as the internal control. Error bars represent $\operatorname{SD}(n=3)$. B A model of BEAR1 function in rice salt response. When rice suffered salt stress, the signal was perceived and transducted to BEAR1. As a transcription activator, BEAR1 induced two class genes, one was in charge of salt response and signal cascade, another was effector genes such as $\mathrm{Na}^{+} / \mathrm{K}^{+}$balance Membrane stabilization. All these genes facilitated rice salt response

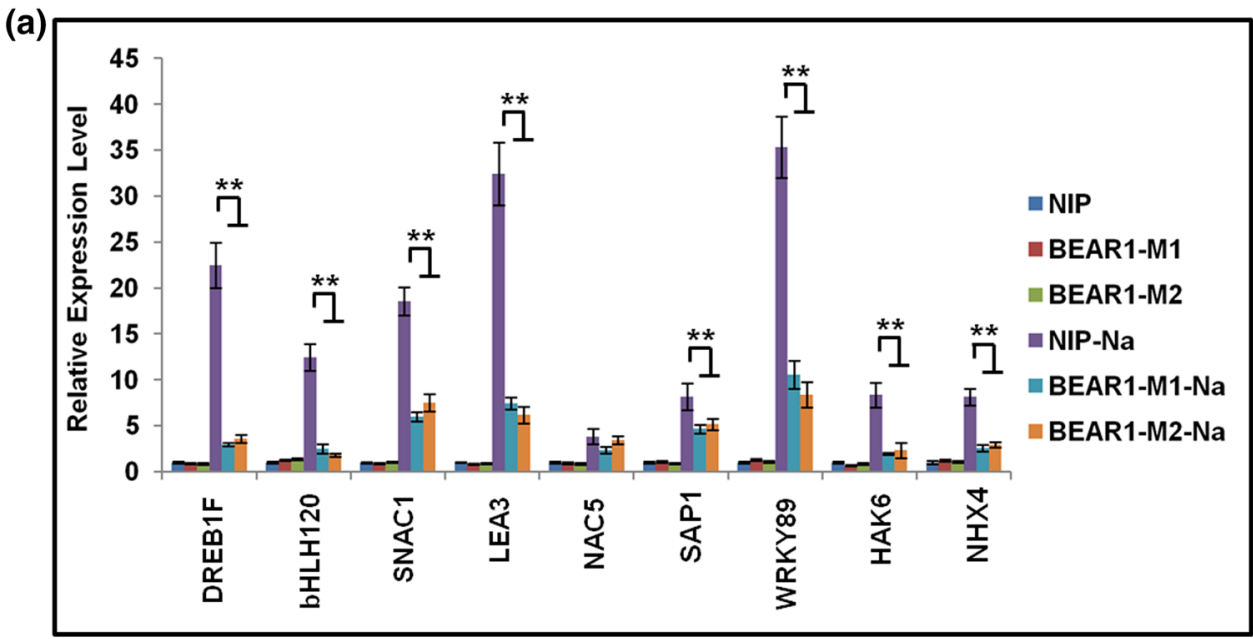

(b)

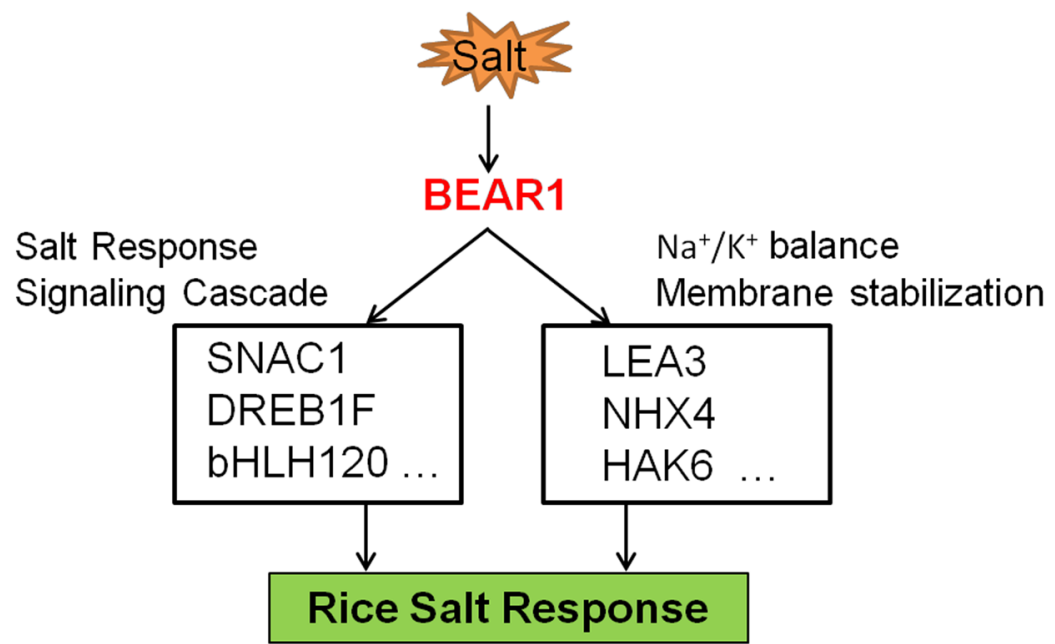

\section{Gene Clone and Vector Construction}

The cDNA library of rice seedling was used to clone BEARI gene. The coding sequence was amplified using primers (Table S1) followed by cloning into the gateway entry vector pENTR-D-TOPO. The destination vectors, pGWB542 and pDEST-GBKT7, were used to generate constructs for subcellular localization and transcription regulation experiments by $L R$ reaction.

\section{Transgenic Plants Generation}

To generate artificial microRNA knockdown lines, pN580 was used as backbone and the whole procedure was described (Ossowski et al. 2008). The generated construct, named as BEAR1-PN580, was transformed into Agrobacterium to infect rice calli. The transgenic plants were named as BEAR1-ami. BEAR1 mutant materials were generated by CRISPR-Cas9 system (Yan et al. 2015). The detailed protocol was followed to generate gene editing constructs, named BEAR1-M1 and BEAR1-M2. The BEAR1 gene editing plants were obtained by Agrobacterium-mediated transformation as BEAR1-ami transgenic plants.

\section{BEAR1 Subcellular Localization}

For localization assay, BEARl was cloned into destination vector pGWB542, the protoplast of rice seedling was isolated by previously described method (Yang et al. 2014). The BEAR1-EYFP fusion proteins were transient expressed in rice protoplast for $16 \mathrm{~h}$ and the fluorescent signals were detected by Zeiss LSM 710 inverted confocal microscope.

\section{Transcription Activity Assay}

$B E A R 1$ from gateway entry vector was introduced into destination vector GBKT7, which was named as pBEAR1. pGBK-VP16 was used as positive control $(\mathrm{CK}+)$ and pGBKT7 was used as negative control (CK-). Constructs were transferred into yeast strain AH109, respectively. The 
transcription activity assay was performed as described in the Clontech yeast protocol PT3024-1.

\section{Deep Sequencing and Data Analysis}

Total RNA was extracted separately from seedling root and leaf with or without $250 \mathrm{mM} \mathrm{NaCl}$ treatment for $3 \mathrm{~h}$. The RNA-seq libraries were constructed using Illimina whole transcriptome analysis kit with standard protocol and quantified the concentration by Qubit 2.0. The library insert size was detected by Agilent 2100. The RNA libraries were sequenced on HiSeq2500 to generate high throughput raw reads. The clean reads were obtained by trimming the raw reads and quality control, followed by mapping to reference genome IRGSP-1.0 using HISAT2. The differentially expressed genes (DEGs) were calculated by DESEQ2 with $P$ value $\leq 0.05$ and fold change $\geq 2$.

\section{RNA Extraction and Gene Expression Analyses}

Total RNA was extracted from 2-week-old seedlings treated with $300 \mathrm{mM} \mathrm{NaCl}$ for $3 \mathrm{~h}$ or water as a control. cDNA libraries were synthesized from total RNA. Real-time qPCR was performed on the ABI QuantStudio5 system using ACT2 as a control. Primers used in this study are presented in Table S1.

Supplementary Information The online version contains supplementary material available at https://doi.org/10.1007/s12374-022-09347-4.

Author contributions YT and ML conducted the study, collected, and analyzed the data. TC designed the study and methods and collected the funds. XZ and MC provided technical assistants. TC prepared manuscript. All authors read and approved the final manuscript.

Funding This work was supported by the grants from the Natural Science Foundation of China (32071932), the National Transgenic Major Program (2019ZX08010-004) and the Starting Research Fund from the Hangzhou Normal University (2019QDL015).

\section{Declarations}

Conflict of interest The authors declare that they have no known competing financial interests or personal relationships that could have appeared to influence the work reported in this paper.

Open Access This article is licensed under a Creative Commons Attribution 4.0 International License, which permits use, sharing, adaptation, distribution and reproduction in any medium or format, as long as you give appropriate credit to the original author(s) and the source, provide a link to the Creative Commons licence, and indicate if changes were made. The images or other third party material in this article are included in the article's Creative Commons licence, unless indicated otherwise in a credit line to the material. If material is not included in the article's Creative Commons licence and your intended use is not permitted by statutory regulation or exceeds the permitted use, you will need to obtain permission directly from the copyright holder. To view a copy of this licence, visit http://creativecommons.org/licenses/by/4.0/.

\section{References}

Abraham E, Hourton-Cabassa C, Erdei L, Szabados L (2010) Methods for determination of proline in plants. Methods Mol Biol 639:317331. https://doi.org/10.1007/978-1-60761-702-0_20

Atchley WR, Terhalle W, Dress A (1999) Positional dependence, cliques, and predictive motifs in the bHLH protein domain. J Mol Evol 48(5):501-516. https://doi.org/10.1007/p100006494

Bermudez MA, Paez-Ochoa MA, Gotor C, Romero LC (2010) Arabidopsis S-sulfocysteine synthase activity is essential for chloroplast function and long-day light-dependent redox control. Plant Cell 22(2):403-416. https://doi.org/10.1105/tpc.109.071985

Carretero-Paulet L, Galstyan A, Roig-Villanova I, Martinez-Garcia JF, Bilbao-Castro JR, Robertson DL (2010) Genome-wide classification and evolutionary analysis of the bHLH family of transcription factors in Arabidopsis, Poplar, Rice, Moss, and Algae. Plant Physiol 153(3):1398-1412. https://doi.org/10.1104/pp.110.153593

Cheng XL, Zhang SX, Tao WC, Zhang XX, Liu J, Sun JQ, Zhang HW, $\mathrm{Pu}$ L, Huang RF, Chen T (2018) INDETERMINATE SPIKELET1 recruits histone deacetylase and a transcriptional repression complex to regulate rice salt tolerance. Plant Physiol 178(2):824-837. https://doi.org/10.1104/pp.18.00324

Cheng XL, He Q, Tang S, Wang HR, Zhang XX, Lv MJ, Liu HF, Gao Q, Zhou Y, Wang Q, Man XY, Liu J, Huang RF, Wang H, Chen T, Liu J (2021) The miR172/IDS1 signaling module confers salt tolerance through maintaining ROS homeostasis in cereal crops. New Phytol 230(3):1017-1033. https://doi.org/10.1111/nph.17211

Cui X, Wang YX, Liu ZW, Wang WL, Li H, Zhuang J (2018) Transcriptome-wide identification and expression profile analysis of the bHLH family genes in Camellia sinensis. Funct Integr Genomics 18(5):489-503. https://doi.org/10.1007/s10142-018-0608-x

Dangoor I, Peled-Zehavi H, Wittenberg G, Danon A (2012) A chloroplast light-regulated oxidative sensor for moderate light intensity in Arabidopsis. Plant Cell 24(5):1894-1906. https://doi.org/10. 1105/tpc.112.097139

Dong Y, Wang CP, Han X, Tang S, Liu S, Xia XL, Yin WL (2014) A novel bHLH transcription factor PebHLH35 from Populus euphratica confers drought tolerance through regulating stomatal development, photosynthesis and growth in Arabidopsis. Biochem Biophys Res Commun 450(1):453-458. https://doi.org/10.1016/j. bbrc.2014.05.139

Ganie SA, Molla KA, Henry RJ, Bhat KV, Mondal TK (2019) Advances in understanding salt tolerance in rice. Theor Appl Genet 132(4):851-870. https://doi.org/10.1007/s00122-019-03301-8

Huang GT, Ma SL, Bai LP, Zhang L, Ma H, Jia P, Liu J, Zhong M, Guo ZF (2012) Signal transduction during cold, salt, and drought stresses in plants. Mol Biol Rep 39(2):969-987. https://doi.org/ 10.1007/s11033-011-0823-1

Kim J, Kim HY (2006) Functional analysis of a calcium-binding transcription factor involved in plant salt stress signaling. FEBS Lett 580(22):5251-5256. https://doi.org/10.1016/j.febslet.2006.08.050

Krishnamurthy P, Vishal B, Khoo K, Rajappa S, Loh CS, Kumar PP (2019) Expression of AoNHX1 increases salt tolerance of rice and Arabidopsis, and bHLH transcription factors regulate AtNHX1 and AtNHX6 in Arabidopsis. Plant Cell Rep 38(10):1299-1315. https://doi.org/10.1007/s00299-019-02450-w

Kumar K, Kumar M, Kim SR, Ryu H, Cho YG (2013) Insights into genomics of salt stress response in rice. Rice (n Y). https://doi. org/10.1186/1939-8433-6-27

Li XX, Duan XP, Jiang HX, Sun YJ, Tang YP, Yuan Z, Guo JK, Liang WQ, Chen L, Yin JY, Ma H, Wang J, Zhang DB (2006) Genomewide analysis of basic/helix-loop-helix transcription factor family in rice and Arabidopsis. Plant Physiol 141(4):1167-1184. https:// doi.org/10.1104/pp.106.080580 
Li F, Guo SY, Zhao YA, Chen DZ, Chong K, Xu YY (2010) Overexpression of a homopeptide repeat-containing bHLH protein gene (OrbHLH001) from Dongxiang Wild Rice confers freezing and salt tolerance in transgenic Arabidopsis. Plant Cell Rep 29(9):977-986. https://doi.org/10.1007/s00299-010-0883-Z

Li DF, Zhang YQ, Hu XN, Shen XY, Ma L, Su Z, Wang T, Dong JL (2011) Transcriptional profiling of Medicago truncatula under salt stress identified a novel CBF transcription factor MtCBF4 that plays an important role in abiotic stress responses. BMC Plant Biol. https://doi.org/10.1186/1471-2229-11-109

Li J, Liu JT, Wang GQ, Cha JY, Li GN, Chen S, Li Z, Guo JH, Zhang CG, Yang YQ, Kim WY, Yun DJ, Schumaker KS, Chen ZZ, Guo Y (2015) A chaperone function of NO CATALASE ACTIVITY1 is required to maintain catalase activity and for multiple stress responses in Arabidopsis. Plant Cell 27(3):908-925. https://doi. org/10.1105/tpc.114.135095

Liu KM, Wang L, Xu YY, Chen N, Ma QB, Li F, Chong K (2007) Overexpression of OsCOIN, a putative cold inducible zinc finger protein, increased tolerance to chilling, salt and drought, and enhanced proline level in rice. Planta 226(4):1007-1016. https:// doi.org/10.1007/s00425-007-0548-5

Liu CT, Mao BG, Ou SJ, Wang W, Liu LC, Wu YB, Chu CC, Wang XP (2014a) OsbZIP71, a bZIP transcription factor, confers salinity and drought tolerance in rice. Plant Mol Biol 84(1-2):19-36. https://doi.org/10.1007/s11103-013-0115-3

Liu WW, Tai HH, Li SS, Gao W, Zhao M, Xie CX, Li WX (2014b) bHLH122 is important for drought and osmotic stress resistance in Arabidopsis and in the repression of ABA catabolism. New Phytol 201(4):1192-1204. https://doi.org/10.1111/nph.12607

Livanos P, Galatis B, Gaitanaki C, Apostolakos P (2014) Phosphorylation of a p38-like MAPK is involved in sensing cellular redox state and drives atypical tubulin polymer assembly in angiosperms. Plant Cell Environ 37(5):1130-1143. https://doi.org/10.1111/pce. 12222

Mallikarjuna G, Mallikarjuna K, Reddy MK, Kaul T (2011) Expression of OsDREB2A transcription factor confers enhanced dehydration and salt stress tolerance in rice (Oryza sativa L.). Biotechnol Lett 33(8):1689-1697. https://doi.org/10.1007/s10529-011-0620-x

Massari ME, Murre C (2000) Helix-loop-helix proteins: regulators of transcription in eucaryotic organisms. Mol Cell Biol 20(2):429440. https://doi.org/10.1128/MCB.20.2.429-440.2000

Miao YC, Lv D, Wang PC, Wang XC, Chen J, Miao C, Song CP (2006) An Arabidopsis glutathione peroxidase functions as both a redox transducer and a scavenger in abscisic acid and drought stress responses. Plant Cell 18(10):2749-2766. https://doi.org/10.1105/ tpc. 106.044230

Miller G, Mittler R (2006) Could heat shock transcription factors function as hydrogen peroxide sensors in plants? Ann Bot 98(2):279288. https://doi.org/10.1093/aob/mcl107

Miller G, Suzuki N, Ciftci-Yilmaz S, Mittler R (2010) Reactive oxygen species homeostasis and signalling during drought and salinity stresses. Plant Cell Environ 33(4):453-467. https://doi.org/10. 1111/j.1365-3040.2009.02041.x

Ossowski S, Schwab R, Weigel D (2008) Gene silencing in plants using artificial microRNAs and other small RNAs. Plant J 53(4):674690. https://doi.org/10.1111/j.1365-313X.2007.03328.x

Qiu DY, Xiao J, Ding XH, Xiong M, Cai M, Cao CL, Li XH, Xu CG, Wang SP (2007) OsWRKY13 mediates rice disease resistance by regulating defense-related genes in salicylate- and jasmonatedependent signaling. Mol Plant-Microbe Interact 20(5):492-499. https://doi.org/10.1094/Mpmi-20-5-0492

Qiu D, Xiao J, Xie W, Liu H, Li X, Xiong L, Wang S (2008) Rice gene network inferred from expression profiling of plants overexpressing OsWRKY13, a positive regulator of disease resistance. Mol Plant 1(3):538-551. https://doi.org/10.1093/mp/ssn012
Todaka D, Nakashima K, Shinozaki K, Yamaguchi-Shinozaki K (2012) Toward understanding transcriptional regulatory networks in abiotic stress responses and tolerance in rice. Rice (n Y). https://doi. org/10.1186/1939-8433-5-6

van Zelm E, Zhang YX, Testerink C (2020) Salt tolerance mechanisms of plants. Annu Rev Plant Biol 71:403-433. https://doi.org/10. 1146/annurev-arplant-050718-100005

Verma D, Jalmi SK, Bhagat PK, Verma N, Sinha AK (2020) A bHLH transcription factor, MYC2, imparts salt intolerance by regulating proline biosynthesis in Arabidopsis. FEBS J 287(12):2560-2576. https://doi.org/10.1111/febs.15157

Wang FB, Zhu H, Chen DH, Li ZJ, Peng RH, Yao QH (2016) A grape bHLH transcription factor gene, VvbHLH1, increases the accumulation of flavonoids and enhances salt and drought tolerance in transgenic Arabidopsis thaliana. Plant Cell Tissue Organ Cult 125(2):387-398. https://doi.org/10.1007/s11240-016-0953-1

Waseem M, Rong XY, Li ZG (2019) Dissecting the role of a basic helix-loop-helix transcription factor, SlbHLH22, under salt and drought stresses in transgenic Solanum lycopersicum L. Front Plant Sci. https://doi.org/10.3389/Fpls.2019.00734

Xiang Y, Tang N, Du H, Ye HY, Xiong LZ (2008) Characterization of OsbZIP23 as a key player of the basic leucine zipper transcription factor family for conferring abscisic acid sensitivity and salinity and drought tolerance in rice. Plant Physiol 148(4):1938-1952. https://doi.org/10.1104/pp.108.128199

Xu WR, Zhang NB, Jiao YT, Li RM, Xiao DM, Wang ZP (2014) The grapevine basic helix-loop-helix (bHLH) transcription factor positively modulates CBF-pathway and confers tolerance to coldstress in Arabidopsis. Mol Biol Rep 41(8):5329-5342. https://doi. org/10.1007/s11033-014-3404-2

Yamaguchi-Shinozaki K, Shinozaki K (2006) Transcriptional regulatory networks in cellular responses and tolerance to dehydration and cold stresses. Annu Rev Plant Biol 57:781-803. https://doi. org/10.1146/annurev.arplant.57.032905.105444

Yan LH, Wei SW, Wu YR, Hu RL, Li HJ, Yang WC, Xie Q (2015) High-efficiency genome editing in arabidopsis using YAO promoter-driven CRISPR/Cas9 system. Mol Plant 8(12):1820-1823. https://doi.org/10.1016/j.molp.2015.10.004

Yang Y, Guo Y (2018) Elucidating the molecular mechanisms mediating plant salt-stress responses. New Phytol 217(2):523-539. https://doi.org/10.1111/nph.14920

Yang A, Dai XY, Zhang WH (2012) A R2R3-type MYB gene, OsMYB2, is involved in salt, cold, and dehydration tolerance in rice. J Exp Bot 63(7):2541-2556. https://doi.org/10.1093/jxb/ err431

Yang JW, Fu JX, Li J, Cheng XL, Li F, Dong JF, Liu ZL, Zhuang CX (2014) A novel co-immunoprecipitation protocol based on protoplast transient gene expression for studying protein-protein interactions in rice. Plant Mol Biol Rep 32(1):153-161. https:// doi.org/10.1007/s11105-013-0633-9

Yu CM, Yan M, Dong HZ, Luo J, Ke YC, Guo AF, Chen YH, Zhang J, Huang XS (2021) Maize bHLH55 functions positively in salt tolerance through modulation of AsA biosynthesis by directly regulating GDP-mannose pathway genes. Plant Sci. https://doi. org/10.1016/j.plantsci.2020.110676

Zhai YQ, Zhang LC, Xia C, Fu SL, Zhao GY, Jia JZ, Kong XY (2016) The wheat transcription factor, TabHLH39, improves tolerance to multiple abiotic stressors in transgenic plants. Biochem Biophys Res Commun 473(4):1321-1327. https://doi.org/10.1016/j.bbrc. 2016.04.071

Zhao Q, Xiang XH, Liu D, Yang AG, Wang YY (2018) Tobacco transcription factor NtbHLH123 confers tolerance to cold stress by regulating the $\mathrm{NtCBF}$ pathway and reactive oxygen species homeostasis. Front Plant Sci. https://doi.org/10.3389/Fpls.2018.00381

Zhu JK (2016) Abiotic stress signaling and responses in plants. Cell 167(2):313-324. https://doi.org/10.1016/j.cell.2016.08.029 